\title{
Evidence-based health care in Nepal: The importance of systematic reviews
}

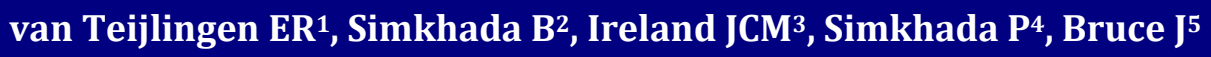

1Professor of Reproductive Health Research, School of Health and Social Care, Bournemouth University, Bournemouth

House, 19 Christchurch Road, Bournemouth, BU1 3LH, United Kingdom.

${ }^{2} \mathrm{PhD}$ graduate, University of Aberdeen, United Kingdom \& Green Tara Nepal, Kathmandu.

${ }^{3}$ Midwife, St Mary's Maternity Unit, Poole Hospital, NHS Foundation Trust, Poole, United Kingdom.

${ }^{4}$ Senior Lecturer in International Health, School of Health and Related Research (ScHARR), University of Sheffield,

Regent Court, 30 Regent Street, Sheffield, S1 4DA, United Kingdom.

${ }^{5}$ Principal Research Fellow, Warwick Clinical Trials Unit, Division of Health Sciences, Warwick Medical School, The

University of Warwick, Coventry, CV4 7AL, United Kingdom.

\section{Review Article}

\section{Corresponding Author:}

Dr. Edwin R van Teijlingen,

Professor of Reproductive Health Research, School of Health and Social Care, Bournemouth University, United Kingdom.

Honorary Professor, University of Aberdeen, Scotland, UK Honorary Visiting Professor, London Metropolitan University, United Kingdom

E-mail: vanteijlingen@bournemouth.ac.uk

\section{Abstract}

Systematic reviewing involves a structured, rigorous, and objective approach to provide a critical synthesis of the available evidence in a particular field. This paper provides a guide to the key steps to undertake a systematic review. It describes the steps to search for relevant literature, provides advice on how to extract data, synthesize and then interpret data during the review process. It also provides the key references and guidelines which are commonly used for systematic review. It is important that researchers conduct and publish systematic reviews to help generate appropriate evidence to interventions and identify gaps in 'local' research. The authors argue that there is a place for systematic reviews in health services research in Nepal. Finally, this paper acknowledges that evidence should be considered within the local health situation and context.
Keywords: Systematic review, Research, Critical appraisal, 10/90 gap

\section{Background}

Producing an evidence-base for best practice in health care and health service provision in developing countries, such as India and Nepal, can make an important contribution to the allocation of scarce resources. It is often found that research studies have been completed in a particular field, but there is no overall synthesis or summary of the evidence with an appraisal of effectiveness or consideration of relevance to the local setting. Systematic reviews do exactly that; they critique and combine evidence on the effectiveness of a particular intervention, drug, procedure or service ${ }^{1,2}$. This process is then summarised and reported in a single publication. Systematic reviewing involves a structured, rigorous, and objective approach to provide a critical synthesis of the available evidence for a specified research question. It requires a thorough, methodical approach with detailed reporting of each stage to ensure transparency and "to overcome the deficiencies of subjectivity, selectivity and timeliness" ${ }^{3}$.

A systematic review is more than a narrative review, as not all literature reviews are necessarily systematic. The process of identifying literature for inclusion in a narrative review may be incomplete and non-systematic. This paper provides a guide to the key steps to undertake a systematic review. It describes the steps to search for relevant literature, provides advice on how to extract epidemiological data, synthesize and then interpret data during the review 
process. Finally, this paper acknowledges that evidence should be considered within the local health situation and context.

\section{Where to start?}

Before you start a systematic review, you must clearly specify the research question of interest. What is it you want to find out? Does your question relate to an intervention, drug, technique or service? Are you interested in risk factors, exposure or interventions? Or are you interested in a particular outcome or long-term consequence of healthcare treatment? Formulating the research question in terms of population, intervention, comparison group (if applicable) and outcome can be helpful, particularly for questions of 'efficacy'. Efficacy refers to whether an intervention or drug works; (often under "ideal" conditions). Effectiveness refers to whether it works in practice ${ }^{4}$. Other research questions may relate to the delivery of care, policy-making or costs of care. The research question will influence the types of studies and study designs to include in your review. Clarifying the research question and deciding on inclusion and exclusion criteria is an essential first step. This process will also help you focus on databases are most appropriate for your topic. Another crucial step is to check whether the question has already been answered. The Cochrane Library, which contains multiple databases including the Cochrane Database of Systematic Reviews (CDSR), is a good starting point to search for summaries of evidence.

\section{Identifying literature}

Start by selecting the secondary information sources, which provide subject access to the relevant range of primary literature. These include electronic bibliographic databases. The National Library of Medicine in the US is the largest medical library in the world (www.nlm.nih.gov/). Box 1 lists the main (but not all) bibliographic databases relating to medicine, nursing, midwifery and health-care literature. These databases contain citations to clinical, pharmaceutical socio-economic, educational and management literature. Some specialist or topic-specific databases are available. For example the Midwives Information and Resources Service (MIDIRS) is a good resource for midwifery and maternity care researchers. Similarly, literature on child trafficking can be found on child trafficking digital library (http://www.childtrafficking.com), which holds over 2500 documents.

\section{Box 1 Bibliographic databases relevant to health research}

- The Cochrane Library

- CINAHL (Cumulative Index of Nursing \& Allied Health Literature)

- MEDLINE via Pubmed (http://www.ncbi.nlm.nih.gov/pubmed/)

- EMBASE

- Science \& Social Science Citation Indexes (ISI Databases)

- PsychINFO

- Applied Social Science Index \& Abstracts (ASSIA)

\section{Access to biomedical databases}

Access to some databases might be a problem for people in Nepal and subscription fees can often be expensive. The National Library of Medicine provides free access to MEDLINE via www.pubmed.com. SCIRUS (http://www.scirus.com/) is a search tool which gives access 440 million scientific records to date (January 2012). The World Health Organization (WHO), together with other major publishers established the Health InterNetwork Access to Research Initiative (HINARI), a programme which allows researchers in developing countries access to an enormous collection of biomedical and health literature. Nearly 4,000 journal titles are now available from 113 countries (see www.who.int/hinari/en/). Institutions in developing countries with a per capita below \$1,250 are eligible for free access. All universities, research institutes, professional training schools (medicine, nursing, pharmacy, public health, and dentistry), teaching hospitals, government offices and national medical libraries in Nepal are eligible to access HINARI. HINARI does not accept registrations from individuals; however, eligible institutions can complete the on-line registration form. A computer with a high-speed Internet connection is needed to access these electronic resources.

In addition to HINARI, there are other initiatives such as AGORA (Access to Global Online Research in Agriculture) administered by the Food and Agriculture Organization (FAO) of the United Nations (UN). AGORA provides access to over 900 key journals in food, nutrition, agriculture and related biological, environmental and social sciences (see: http://www.aginternetwork.org/en). Other initiatives includes the Programme for the Enhancement of Research Information (PERI) (see: http://www.inasp.info/file/105/ access-to-journals-and-research-content.html) or Electronic Information for Libraries (elFL) (see: http://www.eifl.net/ cps/sections/country/armenia/armenia-news/2007_12_17_ developing-new-scholarly) which allow users from developing countries to access online journals free or at low-cost.

Researchers should start by searching electronic databases, but remember that other useful information sources exist, you should consider hand-searching of key journals to identify articles or abstracts not indexed on databases and also check the reference lists of relevant articles identified from your search. Another approach is to ask experts in the area if they are aware of any (un-) published literature.

Apart from published sources there is also a so-called 'grey literature' which is material from organisations not listed on bibliographic databases, thus can be difficult to find. Grey literature includes research reports (from university departments or non-governmental organisations), conference proceedings or government publications. The growth of the Internet means that much of this grey literature can now be accessed. Other useful sources include catalogues of relevant specialist libraries, many of which are accessible on-line. 


\section{Formulation of search strategies}

No single bibliographic database covers the entire literature within a specified subject field. Therefore, for the purpose of a systematic review where you are attempting to retrieve all literature, a search on a single database such as MEDLINE is unlikely to suffice. There is, however, considerable degree of overlap between databases covering similar fields. For example, the European-based EMBASE database provides an alphabetical list of journals indexed on EMBASE that are not indexed by MEDLINE. Box 2 outlines the fundamental principles involved in the formulation of a bibliographic search strategy. These basic steps should be adopted regardless of the database and interface used. Start with a list of terms and keywords synonymous with each concept within your research question. Then identify the corresponding thesaurus or 'controlled' vocabulary terms, where available. This is the list of terms use to index and categorise all publications within a particular database. For example, the thesaurus and controlled vocabulary is called Medical Subject Headings (MeSH) in MEDLINE. Remember that different databases use different thesauri and separate strategies must be formulated for each database. A useful step is to check the controlled terms that were used to index a relevant paper you already have in file. Occasionally there might not be a suitable or specific indexing term available and this will require the introduction of free-text terms. Some databases do not provide thesauri at all, and therefore free-text searching alone must be used. It is always worth contacting a trained librarian for recommendations on controlled versus free-text searching. They will also provide advice on the use of limiting commands and advanced searching techniques, including Boolean operators, truncation, proximity searching and wildcards. Wildcards can allow for differences in spelling when building your search strategy (e.g. labour/labor).

Box 2. Basic principles for formulating a bibliographic database search strategy

- Define the research question and state in words

- Break question down into separate component concepts

- Identify limiting parameters e.g. study design, language, publication type(s), age group etc.

- Identify controlled vocabulary/MeSH terms which correspond to each concept

- Identify free text terms (words in titles/ abstracts), where required, which correspond to individual concepts

- Combine component parts using Boolean logic (AND, OR, NOT operators)

- Apply limiting parameters e.g. language, publication type, gender

\section{Data management}

A systematic review generates a large number of references and a bibliographic management programme such as RefWorks, Procite or Reference Manager can assist with document management and control. These databases can store references, help you keep track of document delivery and can generate a bibliography. It is advisable to keep a 'search diary' recording sources searched and the rationale used during the construction of the strategy. Reporting of the search strategy, databases and other sources should be explicit, with details of limiters applied e.g. time and language. It is customary to reproduce search strategies in an appendix in final reports; this is often a requirement from funders.

\section{Assessment of quality}

Once literature has been retrieved, articles should be read in full and assessed for eligibility for inclusion. Articles should be critically appraised for methodological quality and potential sources of bias. Not all research is conducted to a high standard and results from studies of poor quality should be either rejected or given lower weighting than those of higher quality. Numerous checklists and quality assessment tools have been published for particular study designs e.g. randomised controlled trials (RCTs), cohort studies and surveys (visit www.cebm.net). For example, for health promotion intervention studies you can use the internationally accepted criteria for the systematic review of health promotion ${ }^{5}$, whilst for qualitative studies, the CASP (Critical Appraisal Skills Programme) is commonly used (http://www.phru.nhs.uk/Pages/PHD/CASP.htm). Similarly, you can use HTA (Health Technology Assessment) guideline to review the RCTs and other studies ${ }^{6}$. Ideally, two researchers should assess study quality and extract data independently, resolving discrepancies by discussion or by asking a third reviewer.

\section{Summarise your findings}

Relevant data should be extracted and recorded on data collection forms or electronic spreadsheets. Decisions about which data are to be extracted should be determined prior to the review. This may include: details of population studied, setting, study sample size, intervention or exposure, comparison group, outcome, results and comments. Quantitative data should be extracted from individual studies and, where applicable, can be used to obtain a summed or overall estimate of effect. Metaanalysis is a quantitative method for combing the results of several independent studies that measure the same outcome $^{7}$. A common misconception is that systematic reviews must include a meta-analysis; however, it can often be inappropriate to combine studies numerically, particularly if they are diverse and mixed methodological quality. Many systematic reviews provide a narrative overview of findings, particularly where individual included studies have different study designs, patient characteristics and outcomes ${ }^{7}$. 
Table 1 Example of table to synthesise evidence from primary studies (ANC)

\begin{tabular}{|c|c|c|c|c|}
\hline Reference & Location & $\begin{array}{l}\text { Study } \\
\text { design }\end{array}$ & $\begin{array}{l}\text { Study population / } \\
\text { sample size }\end{array}$ & Results \\
\hline $\begin{array}{l}\text { Author(s), } \\
\text { Year of } \\
\text { publication }\end{array}$ & $\begin{array}{l}\text { Country/ } \\
\text { region }\end{array}$ & $\begin{array}{l}\text { Type of } \\
\text { study, e.g. } \\
\text { cohort or } \\
\text { cross- } \\
\text { sectional } \\
\text { survey }\end{array}$ & $\begin{array}{l}\text { Sample details: } \\
\text { age, parity, socio- } \\
\text { economic status, } \\
\text { urban/rural setting } \\
\text { etc.; number of } \\
\text { subjects }\end{array}$ & $\begin{array}{l}\text { Factors affecting use of } \\
\text { antenatal care and the } \\
\text { direction of effect, and } \\
\text { level of statistical } \\
\text { significance }\end{array}$ \\
\hline $\begin{array}{l}\text { Bhatia \& } \\
\text { Cleland } \\
(1995)\end{array}$ & India & $\begin{array}{l}\text { Cross- } \\
\text { sectional } \\
\text { survey } 1993\end{array}$ & $\begin{array}{l}3,595 \text { currently } \\
\text { married women } \\
\text { aged under } 35 \\
\text { years }\end{array}$ & $\begin{array}{l}\text { - } \text { Obstetric history } \\
\text { ( } \mathrm{p}<0.05 \text { ), (prior foetal } \\
\text { loss+neonatal death)-(it } \\
\text { means the more } \\
\text { obstetric complication, } \\
\text { the more likely go for } \\
\text { ANC) } \\
\text { - Personal hygiene-( } p< \\
0.001 \text { ) (it means, the } \\
\text { better the personal } \\
\text { hygiene, more likely to } \\
\text { go for ANC) }\end{array}$ \\
\hline $\begin{array}{l}\text { Glei et al. } \\
(2003)\end{array}$ & Guatemala & $\begin{array}{l}\text { Guatemalan } \\
\text { Survey of } \\
\text { Family } \\
\text { Health } 1995\end{array}$ & $\begin{array}{l}2,872 \text { women aged } \\
18-35 \text { whose last } \\
\text { two live births } \\
\text { occurred within } \\
\text { five years }\end{array}$ & $\begin{array}{l}-\downarrow \text { Parity(high)-p }<0.001 \text {, } \\
\text { (it means, the higher the } \\
\text { parity, less likely go for } \\
\text { ANC) } \\
\text { - } \uparrow \text { Women's education- } \\
\text { p<0.01, women with } \\
\text { higher education, } \\
\text { women are more likely } \\
\text { go for ANC) }\end{array}$ \\
\hline
\end{tabular}

Table 1 provides an example of variables for extraction, although data summaries will depend on your research question and study design of primary studies. Table 1 has been constructed and simplified using data from a recent systematic review published by Simkhada and colleagues ${ }^{8}$ to illustrate to the reader the use of an overview of research data from different studies included in a single review. This review investigated the main factors associated with the utilisation of antenatal care in developing countries. The 28 studies included in this review identified many common factors affecting antenatal care uptake, for example, maternal education, availability, cost, household income and media exposure. One of the overall conclusions was that cultural beliefs about pregnancy had an influence on antenatal care use whereas parity had a significant negative effect on attendance for care. Table 1 details some the studies that contributed to this conclusion.

If systematic reviews conclude that there is insufficient evidence for a research question, then this is also an important finding as can identify a need for future research. For example, a systematic review of healthy eating interventions in pregnant women and women of childbearing age concluded that:

"evidence was insufficiently robust to recommend immediate implementation of the intervention without further, more rigorous, evaluations to assess the repeatability of the findings, the true magnitude of the changes and whether they are sustained over time." 9 .

This does not mean that such interventions are ineffective; rather the current evidence is of poor quality and further more rigorous studies are needed to answer the research question with certainty. Findings of systematic reviews have to be interpreted and discussed in relation to current knowledge and the clinical context. Systematic reviews are useful for identifying gaps in current knowledge and they can help focus future research.

\section{Why conduct systematic reviews in Nepal?}

If systematic reviews aim to bring together the best evidence, you can ask: "What is the specific advantage of applying this research method in Nepal?" One good reason for this is that is generally accepted that local knowledge is a key element in the study of health policy, services and systems. Therefore, "domestic research and analytical capacity are essential not only to implement research that addresses policy-makers' concerns but also to synthesize research findings, assess their relevance to the local context and provide advice as needed ${ }^{10}$. Hence it is important that Nepalese researchers conduct and published systematic reviews to help generate appropriate evidence to interventions and identified gaps in 'local' or 'regional' research. In addition it will help to close North-South gap in health research. Given that less than $10 \%$ of spending on health research world-wide is aimed at diseases or conditions which accounts for $90 \%$ of the global disease burden; this is referred to as the $10 / 90$ gap.

However, there have been global attempts to improve this situation. When it comes to systematic reviewing we see that this method is being used by researchers in a range of developing countries. For example, the Centre for Systematic Review (CSR) was especially established to produce systematic reviews of non-state sector health system issues in low-income and middle-income countries (see: $\quad$ www.icddrb.org/activity/?typeOfActivity=CSR). Worldwide the CSR established four centres to conduct systematic reviews each focussing on one aspect of health systems research. For example one of these is the Centre for Health Management and Policy at Shandong University in China ${ }^{11}$, which specialises in systematic reviews on the effectiveness of various interventions aimed to improve the funding of health systems.

\section{Box 3 Summary of systematic review process}

- Search for existing reviews to check whether question has already been answered

- Develop protocol, refine research question, specify inclusion and exclusion criteria

- Pilot and develop search strategies on bibliographic databases.

- Hand-search selected journals yielding a high frequency of relevant literature.

- Search grey literature and contact other experts in field (e.g. email request to discussion groups such as midwifery-research@jiscmail.ac.uk )

- Critical appraisal of abstracts by two independent 


\section{researchers}

- Obtain full copy of studies for inclusion (photocopies/ inter-library loans)

- Extract data and assess quality of included studies (two independent researchers)

- Resolve differences about methodological quality / inclusion and exclusion

- Synthesise data and interpret findings

- Write full report

- Interpret findings, consider wider research and policy implications and contribution to existing knowledge

\section{Conclusion}

This introductory article outlines the key steps to follow when conducting a systematic review. Each step in this procedure is listed in Box 3 . Health care practitioners may be limited by time and resources when conducting reviews; however a systematic and transparent approach should be adopted wherever possible. Further detailed guidance on systematic reviews is available without cost online from the NHS Centre for Reviews and Dissemination (NHS CRD, 2009) $)^{12}$ and the Cochrane Handbook for Systematic Reviews Interventions $^{13}$. It is important that Nepalese researchers conduct and publish systematic reviews to generate evidence about interventions and identify gaps in the 'local' health and research setting. In addition, improving the rigour of health services and related research will help to address the North-South gap.

\section{Authors' contributions}

EvT taught systematic reviewing in Nepal, drafted the paper, and improved the manuscript, BS designed Table 1, and improved the manuscript, $\mathrm{Jl}$ helped draft the paper and improved the manuscript, PS taught systematic reviewing in Nepal, and improved the manuscript, JB taught systematic reviewing in Nepal, and improved the manuscript.

\section{References}

1. Teijlingen van E, Napper M, Bruce J, Ireland J. Systematic reviews in midwifery, RCM Midwives J 2006; 9: 186-8.

2. Petticrew $M$, Roberts $H$. Systematic reviews in the social sciences: a practical guide. Oxford: Blackwell Publishing, 2006.

3. Cullinan P. Evidence-based health care: systematic reviews. In: Bowling A, Ebrahim S eds. Handbook of Health Research methods: Investigation, measurement and analysis. Maidenhead: Open University Press, 2005, pp 47.

4. Crombie IK, Davies HTO. Research in healthcare: design, conduct and interpretation of health services research. Chichester: Wiley, 1996.

5. Jackson N, Waters E. Criteria for the systematic review of health promotion and public health interventions. Health Promotion Internat 2005; 20: 367-74.

6. Sutton A, Abrams K, Jones K, Sheldon T, Song F. Systematic reviews of trials and other studies. Health Nepal Journal of Epidemiology 2011;1(4): 114-118
Technology Assessment 1998; 2: 19. (Available from: http://www.ncchta.org/fullmono/mon219.pdf).

7. Bruce J, Mollison J. Reviewing the literature: adopting a systematic approach. J Fam Plann Reprod Health Care 2004; 30: 13-6.

8. Simkhada B, van Teijlingen E, Porter M, Simkhada P. Factors affecting the utilisation of antenatal care in developing countries: a systematic review of the literature. J Advanced Nurs 2007; 61: 244-60.

9. Teijlingen van ER, Wilson BJ, Barry N, et al. Effectiveness of interventions to promote healthy eating in pregnant women and women of childbearing age: a review. London: HEA, 1998, pp 3.

10 Alliance for Health Policy \& Systems Research. Riding a Wave of Change: Annual Report 2007. Geneva: WHO. [online] 2008 [ cited 2011 july 1] Available from: URL:http://www.who.int/alliance-hpsr/en/

11. Centre for Systematic Review (CSR). Collaborating Partners: Centre for Health Management and Policy, Shandong University, People's Republic of China. [online] 2011 [ cited 2011 Jun 13] Available from: URL:http://www.icddrb.org/activity/index.jsp?activityObjec $\mathrm{tID}=828$

12. NHS Centre for Reviews and Dissemination (CRD). Systematic reviews: CRD's guidance for undertaking reviews in healthcare. York: NHS Centre for Reviews and Dissemination. [online] 2009 [ cited 2011 August 13] Available from: URL:http://www.york.ac.uk/inst/crd /index_guidance.htm

13. The Cochrane Collaboration. Cochrane Handbook for Systematic Reviews of Interventions. [online] 2009 [ cited 2011 August 13] Available from: URL:http:// www. cochrane.org/training/cochrane-handbook.

\begin{tabular}{|c|c|}
\hline \multicolumn{2}{|c|}{ Article Information } \\
\hline \multicolumn{2}{|c|}{ Article history } \\
\hline Received & 01 September 2011 \\
\hline Received in revised form & 20 September 2011 \\
\hline Accepted & 25 September 2011 \\
\hline
\end{tabular}

